\title{
DETERMINING TACTICAL OPERATIONAL PLANNING POLICIES FOR AN AUTO CARRIER - A CASE STUDY
}

\author{
A.J. du Plessis ${ }^{1}$ and J. Bekker ${ }^{2 *}$ \\ 1,2 Department of Industrial Engineering \\ University of Stellenbosch, South Africa \\ aduplessis@bwlog.com, jb2@sun.ac.za
}

\begin{abstract}
This study was done to assist a local auto carrier company with tactical operational planning. The objective of the planning process is to maximise the number of vehicles delivered while being on time and adhering to staff and maintenance schedule constraints.

We investigated the feasibility of allowing part of the fleet to roam the closed spatial network, as opposed to the traditional assignment of the complete fleet to fixed routes. We developed decision-making rules for roaming and fixed-to-route auto carriers, and evaluated the quality of these proposed rules, in combination with different fleet compositions, using discrete event simulation and four performance measures.
\end{abstract}

We found that the auto carrier company should adopt a tactical operations policy where at least $50 \%$ of the fleet is allowed to roam, while roaming auto carriers pick vehicles to transport according to specific rules.

\section{OPSOMMING}

Hierdie studie is gedoen om 'n plaaslike motorvervoer-onderneming te help met taktiese bedryfsbeplanning. Die doelwit van die beplanningsproses is om die aantal voertuie wat betyds afgelewer word te maksimeer met inagneming van personeel- en instandhoudingbeperkings. Ons het die moontlikheid dat ' $n$ deel van die vragmotorvloot swerwend in die geslote ruimtelike roete-network moet opereer, ondersoek. Dit is in teenstelling met die tradisionele vaste toedeling van vragmotors aan roetes. Besluitnemingreëls vir swerwende en vaste-roete vragmotors is ontwikkel, en die gehalte van die reëls is met diskrete simulasie en vier prestasiemaatstawwe evalueer.

Ons het bevind dat die vervoeronderneming 'n bedryfsbeleid behoort te aanvaar wat toelaat dat ten minste $50 \%$ van die vloot swerf, terwyl hierdie swerwende vragmotors voertuie volgens spesifieke reëls by oplaaipunte moet kies.

\footnotetext{
1 The author was enrolled for an M Sc Eng (Industrial) degree in the Department of Industrial Engineering, University of Stellenbosch.

${ }^{*}$ Corresponding author
} 


\section{INTRODUCTION}

In this case study, we present a set of guidelines that were developed to assist decision makers with the transportation planning and execution of a specific type of freight, namely vehicles. These include passenger cars, pick-up trucks, vans, and sports utility vehicles (SUVs). The problem originated with a South African transportation operator. We refer to this operator as an auto carrier company (AC company) that uses auto carriers (ACs) to transport the vehicles. An auto carrier is defined as a truck with a tractor and a trailer, a special tractor-trailer rig, which presents upper and lower loading planes (Tadei et al. [24]). The purpose of the delivery operation in this study is to distribute the vehicles by road over great distances from ports of import and auto manufacturers to the retail dealerships where the vehicles are sold. Delivering cars, trucks, or vans to auto dealerships is a specialised problem in the routing and scheduling problem class. The challenging problems in freight transportation, and their suitability for applying scientific methodologies, resulted in research over a wide spectrum. This research covers vehicle routing problems with their variants and solution approaches (Laporte [12]; Laporte et al. [13]; Toth and Vigo [26]), freight flow planning (Moreno-Quintero [19]), service network design (Andersen et al. [2]), and integrated transportation planning that extends vehicle routing and scheduling by adding the possibility of contracting outsourced fleets (Krajewska and Kopfer [11]). Mes et al. [17] introduced agent-based scheduling of full truckload orders with time windows, and identified the need for a flexible, stable, and robust planning and control system. Yang et al. [28] provide an overview of the literature covering research in pick-up and delivery problems.

When the planning time span is considered, freight transportation problems can be classified on three levels: strategic, tactical, and operational (Crainic and Laporte[6]; Wu et al.[27]). Planning on the strategic level has long-term implications and requires a substantial financial commitment, while tactical planning focuses on the medium term, and operational planning on the short term. Each level contains problem subclasses; some are shown in Figure 1.

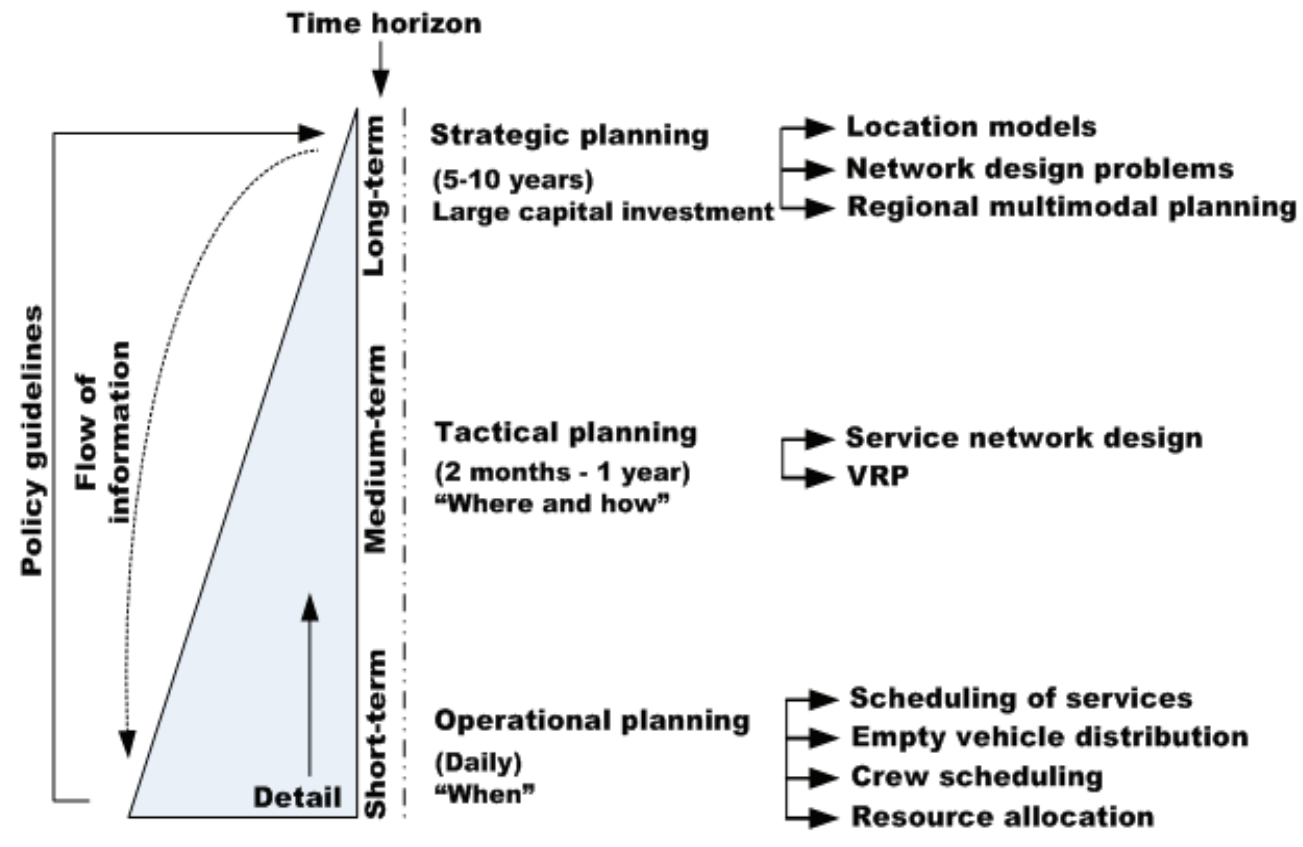

Figure 1: Overview of freight problems and planning levels 
We developed and evaluated decision guidelines that apply on the operational and tactical planning levels for a specific AC company, and present these, together with the results, in this paper. Sörensen (2006) argues that vehicle routing decisions should be stable and not change too often; hence our focus on developing and evaluating some policies on the tactical level.

This paper is structured as follows: In Section 2 auto carrier operations and the main constraints are discussed, followed by a brief overview in Section 3 of work already done in this specific field. In Section 4 we state the requirements for this study, followed by a description in Section 5 of the design of the specific operational policies developed for the AC company. The various policies were evaluated using discrete event simulation, which we discuss in Section 6. We also identify and explain the policy evaluation parameters in this section. An important requirement of this study was to investigate the possibility of having roaming auto carriers - i.e. units that are not fixed to routes - and, if feasible, what proportion of the fleet should be allowed to roam the transportation network. Various fleet compositions, in combination with the designed operational policies, were evaluated, and the results are presented in Section 7. Refinement of the results leads to the introduction of an analogue to the efficient frontier as outlined in Section 8. A summary and conclusions follow in Section 9.

\section{AUTO CARRIER OPERATIONS AND MAIN CONSTRAINTS}

The need for vehicle transportation exists because a dealership sells vehicles to the public and orders these from local or overseas manufacturers. A manufacturer contracts the $A C$ company (or its concurrents) to pick up the vehicles at the port of import or the local manufacturing plant and distribute them via main branches to the dealers throughout a geographical area. The AC company has branches in major centres where they can store vehicles temporarily, and facilitate loading and unloading of regional and long-distance auto carriers. Since the orders of individual dealers are usually small, smaller auto carriers transporting three to four vehicles each are used for these regional deliveries. Regional operations were excluded from this study.

Each order, as it is placed with the auto carrier, has specific attributes. These include the number and types of vehicles to be distributed, the release date, destination, origin, and desired delivery date of each vehicle. Flow of vehicles (orders) may occur between any two branches in the network, while the flow is usually imbalanced, i.e. some branches have a higher demand than others.

The AC company is allowed five calendar days to deliver the vehicles. If the vehicles are delivered after the specified date, a penalty cost may be incurred and/or the manufacturer may lose confidence in the service offered and contract another AC company. The auto carrier operation has to accommodate other factors as well: South African labour legislation and traffic regulations require that truck drivers (including auto carrier drivers) rest at least six hours per day, specifically from 23:00 until 05:00. After 14 work days, drivers must be home for two consecutive days. Auto carriers must also return to the central scheduling depot (CSD) for compulsory maintenance after every $22,000 \mathrm{~km}$ travelled.

The scheduling of the long-distance carriers is currently done at the CSD. The CSD receives information from the individual branches and some manufacturers, and compiles a schedule according to which long-distance carriers are employed on the fixed long-distance routes. Varying order sizes and types, when orders arise, and when they are to be delivered, as well as when vehicles are ready for pick-up at the local manufacturer or port of import, add to the complexity of routing, scheduling, and overall auto carrier fleet management. Currently scheduling is done using informal heuristics based on experience and management prescription.

The AC company in our study owns 140 long-distance auto carriers operating in a closed, spatial network of routes covering thousands of kilometres. Each long-distance auto carrier 
has a standard capacity of 11 vehicle slots, but the vehicles to be moved vary in size, with the result that a load of 7 to 11 vehicles can be accepted at a time, making the loads nonhomogenous. An SUV may, for example, take up the equivalent of one and a half slots, while a small car occupies one slot; together these two vehicles will occupy three slots.

\section{PROBLEM-SPECIFIC LITERATURE}

Having stated the AC problem briefly, we now consider specific literature in this field. Auto carrier specific studies in the literature seem to be fairly limited, mainly involving planning and scheduling on an operational level. Heuristics, algorithms, and/or software are developed to aid the loading and/or routing aspects of the auto carrier problem. The loading problem is significant, since deliveries to dealers usually require that the vehicles of only one dealer are placed on a single auto carrier. Additionally, the cost of reloading can be significant. The driver has to be paid for a reload, and the risk of damaging the vehicles during handling is increased. The loading problem is addressed in a study by Agbegha et al. [1], where the main focus of their work is the formulation and solution of the loading problem. The complexity of this problem is due to the fact that when an auto carrier is used to deliver vehicles to more than one dealer from a single load, the vehicles should be loaded in a sequence that minimizes the unloading of some vehicles in order to gain access to others. Vehicles also vary in size and height, and they have to be assigned to slots in a configuration that will not violate the space restrictions.

Tadei et al.[24] developed a three-step heuristic procedure, strongly based on integer programming, to aid the loading, vehicle selection, and routing aspects of auto carrier functioning. Whereas Agbegha et al.[1] only addressed the loading methodology without considering unloading stops and routing aspects, Tadei et al.[24] developed a mixed integer program that considers both loading and scheduling aspects, to ensure good auto carrier fleet routing and functioning. The proposed model outperformed manual solutions by about $3 \%$.

A more generalised problem that strongly relates to this study is described by Yang et al.[28]. They developed optimising policies for a generic real-time multi-vehicle truckload pick-up and delivery problem (TPDP) in which a sequence of job requests provides the exogenous stimulus of the system. Their solution considers costs associated with empty distances travelled, job (order) lateness, and job rejections. They assumed that each truck can carry only one job at a time and that the truck cannot serve another request unless the current delivery is completed. Also, a pool of $N$ jobs is available, of which $A$ of these have to be served. They first formulated an off-line problem in the form of a mixed integer program, followed by real-time policies, which were evaluated using simulation. Powell et al.[20] dynamically assign drivers to cover a sequence of tasks while adhering to (for example) regulations on working hours, and route planning is done frequently and quickly. In a study similar to ours, Doerner at al.[7] combine aspects of sequencing and routing.

The specifics of this study are described next.

\section{REQUIREMENTS FOR THIS STUDY}

The AC company had a particular need for formal tactical decision-making policies regarding the application of their long-distance auto carriers. The proposed approach was to introduce flexibility on the long-distance routes by employing auto carriers as roaming or fixed. Fixed means that auto carriers persist on predefined routes, usually between two branches, whereas roaming auto carriers rely on dynamic decision-making, providing service where needed, if possible. It follows that the best fleet composition had to be determined, i.e. what numbers of the limited auto carrier resource should be roaming or fixed in order to incur the most benefit and the lowest costs and fewest penalties. It also follows that local operational rules were required for the roaming fleet, because the driver of a roaming auto carrier that arrives at a given branch (node in the network) must be able to decide what to do next, while fixed auto carriers follow rigid rules. 
Several operational rules were developed during this study, which dictate and prescribe roaming auto carrier behaviour and decision-making. Rules are combined to form various operational policies, and for a particular policy the most suitable fleet composition (proportion of fixed and roaming) must be determined. Different combinations of policies and fleet compositions can therefore be evaluated by means of a criterion or multiple criteria, in order to decide on the best combination. Andersen et al.[2] did similar work by focusing on multiple fleets - i.e., additional fleets can be subcontracted to address varying demand. However, in this study the auto carriers come from the same pool of 140 similar units.

Our problem is essentially one of assigning the 140 resources to unevenly distributed tasks that emerge and are served over time, in a dynamic way (Carvalho and Powell[5]; Wu et al.[27]). The transportation network is stochastic and dynamic, having practical constraints. These include mandatory maintenance of auto carriers at the CSD after every 22,000 km travelled, while we also accommodated the specific labour requirements relating to auto carrier drivers. As mentioned earlier, drivers may not be on the road between 23:00 and 05:00, and must be at home for two days after 14 days of work.

The operational policies designed to manage the auto carrier fleet on a tactical level are now presented.

\section{DESIGN OF THE TACTICAL OPERATIONAL PLANNING POLICIES}

The different operational planning policies consist of rules that dictate roaming auto carrier behaviour. These rules specifically determine how orders at the current branch will be picked for loading, and also whether or not an auto carrier should wait at the branch for future but unknown orders. The rules are grouped in two policy classes: 1) roaming orderpicking, and 2) waiting policies. The rules in the first class allow drivers dynamically to decide what to do at a branch; a similar problem has been addressed by Powell et al.[20] who developed algorithms to plan dynamically for the drivers.

Hickman[9] studied the transit vehicle holding problem, which relates to the second policy class. Branke et al.[4] suggested waiting strategies for the dynamic vehicle routing problem, and considered the arrival of one additional customer after vehicles have been dispatched. Thomas[25] used a Markov decision process and heuristics to determine where a vehicle should wait in anticipation of stochastic service requests to increase the number of customers served by a single vehicle. Mitrović-Minić and Laporte[18] developed four waiting strategies for the dynamic pickup and delivery problem with time windows. Their simplest strategies are also extreme: these are the drive-first waiting strategy (a vehicle must depart as soon as possible from its current location) and wait-first waiting strategy (a vehicle must wait for as long as possible at its current location). Branke et al.[4] argued that if the number of new customers (new orders in our case) is large, waiting is unlikely to be of benefit. Currently the AC company uses the wait-first waiting strategy, but given the above arguments, we introduced the drive-first waiting strategy in some policies. The policy classes that were developed consist of the rules summarised in Table 1.

An operational rule from each policy class is combined to constitute an operational planning policy - for instance: roaming auto carriers do not need to wait for work at any location (rule 2.a), but if there is work, the roaming auto carriers pick vehicles according to rule 1.b.

The roaming auto carrier order-picking and waiting policy rules were combined to construct nine different operational policies. For each of the nine policies, different fleet compositions are possible, since the 140 available long-distance auto carriers may be used as either fixed or roaming. Roaming auto carriers are used where needed, and attend to peaks in the demand. The question now is what the sizes of the roaming and fixed carrier fleets should be - in other words, how many of the available auto carriers should be used as 
roaming and how many as fixed. In order to investigate this, different fleet compositions were examined for each operational planning policy.

\begin{tabular}{|c|c|c|c|}
\hline $\begin{array}{l}\text { Policy } \\
\text { class }\end{array}$ & $\begin{array}{l}\text { Sub- } \\
\text { class }\end{array}$ & Operational rule & Description \\
\hline \multirow[t]{3}{*}{1} & $a$ & $\begin{array}{l}\text { Pick vehicles with } \\
\text { destination where } \\
\text { majority of vehicles } \\
\text { have to go. }\end{array}$ & $\begin{array}{l}\text { A roaming auto carrier at current location } b_{i} \\
\text { selects vehicles from queue } b_{i} \text { with destination } \\
b_{j} \text {, where the majority of vehicles in queue } b_{i} \\
\text { have to go to } b_{j} \text {. That is, } b_{j} \leftarrow \max _{\mathrm{bj}}\left\{n\left(b_{j}\right)\right\} \text { where } \\
n\left(b_{j}\right) \text { is the number of vehicles destined for } b_{j} \text {. }\end{array}$ \\
\hline & $\mathrm{b}$ & $\begin{array}{l}\text { Pick vehicles with } \\
\text { highest priority. }\end{array}$ & $\begin{array}{l}\text { A roaming auto carrier at current location } b_{i} \\
\text { selects vehicles from the queue at } b_{i} \text { with } \\
\text { destination } b_{j} \text {, where the vehicles have the } \\
\text { highest rank in the queue, and the sum of the } \\
\text { waiting time is the greatest for a particular } \\
\text { destination } b_{j} \text {. That is, } \\
b_{j} \leftarrow \max _{b_{j}}\left\{0.5 \frac{T_{j}}{T}+0.5 \frac{\sum_{b_{j}}\left(q_{i}-k\right)}{q_{i}}\right\} \\
\text { where } T_{j} \text { is the total waiting time of cars at } b_{i} \\
\text { and destined for } b_{j}, T \text { is the maximum of these } \\
\text { times, } q_{i} \text { is the number of vehicles waiting at } b_{i} \text {, } \\
\text { and } k \text { is the rank of each vehicle destined for } b_{j} \\
\left(1 \leq k \leq q_{i}\right) \text {. }\end{array}$ \\
\hline & C & $\begin{array}{l}\text { Pick vehicles where } \\
\text { majority of vehicles } \\
\text { have to go to } \\
\text { closest destination. }\end{array}$ & $\begin{array}{l}\text { A roaming auto carrier at the current location } b_{i} \\
\text { selects vehicles from the queue at } b_{i} \text { with } \\
\text { destination } b_{j} \text {, where the majority of vehicles } \\
\text { have to go to the same destination and the } \\
\text { selected destination is closest to the current } \\
\text { location. That is, } \\
b_{j} \leftarrow \max _{b_{j}}\left\{\frac{n\left(b_{j}\right)}{D\left(b_{j}\right)}\right\} \\
\text { where } n\left(b_{j}\right) \text { is the number of vehicles destined } \\
\text { for } b_{j} \text { and } D\left(b_{j}\right) \text { is the distance from } b_{i} \text { to } b_{j} \text {. }\end{array}$ \\
\hline \multirow[t]{3}{*}{2} & $a$ & $\begin{array}{l}\text { Roaming: no wait } \\
\text { policy. }\end{array}$ & $\begin{array}{l}\text { When there is no work at the current location, a } \\
\text { roaming auto carrier may depart empty and } \\
\text { selects the next best destination by investigating } \\
\text { the amount of work at each destination. }\end{array}$ \\
\hline & $\mathrm{b}$ & $\begin{array}{l}\text { Roaming and Fixed: } \\
\text { no wait policy. }\end{array}$ & $\begin{array}{l}\text { If the current location } b_{i} \text { has no work, fixed auto } \\
\text { carriers simply depart for the next planned } \\
\text { branch in their sequence, and roaming auto } \\
\text { carriers depart for the next destination with } \\
\text { most work. }\end{array}$ \\
\hline & C & $\begin{array}{l}\text { No waiting at minor } \\
\text { branches } \\
\text { (branches with } \\
\text { lower volumes). }\end{array}$ & $\begin{array}{l}\text { Fixed and roaming auto carriers may depart } \\
\text { empty from minor branches and do not wait for } \\
\text { work at these branches. }\end{array}$ \\
\hline
\end{tabular}

Table 1: Policy rule descriptions

Five different fleet compositions were identified for this purpose:

- $\quad 0 \%$ Roaming, $100 \%$ Fixed (where $100 \%$ implies 140 auto carriers)

- $\quad 25 \%$ Roaming, $75 \%$ Fixed

- $\quad 50 \%$ Roaming, $50 \%$ Fixed

- $\quad 75 \%$ Roaming, 25\% Fixed

- $100 \%$ Roaming, 0\% Fixed 
The numbers of fixed auto carriers, once determined, have to be assigned to the fixed routes. When the fleet composition is $25 \%$ Roaming, for example, the remaining $75 \%$ auto carriers are employed as Fixed, and have to be allocated to fixed sequences of destinations which they traverse in cyclic fashion. For the purpose of this study, fixed auto carriers were assigned proportionally based on the $75^{\text {th }}$ percentile of historical demand on the routes. If, for example, the $75^{\text {th }}$ percentile on route $A-B$ was $p_{A-B}$ based on observations over the past six months, and the sum of the percentiles on all routes is $S_{p}$, then the integral value of [140 carriers $\times 75 \%$ Fixed $\times p_{A-B} / S_{p}$ ] auto carriers are assigned to route $A-B$. This percentile has been arbitrarily selected to avoid using absolute observed maximums, and its sensitivity should be further studied.

The selection of the fleet compositions results in five alternatives and, combined with the nine policy combinations, leads to 45 scenarios. The quality and potential benefit of each scenario were evaluated using discrete event simulation, as explained next.

\section{EVALUATING THE SCENARIOS USING SIMULATION}

Simulation provides a convenient analysis framework when analysing complex, dynamic, and stochastic problems. Many system interactions and timings can be represented to determine infrastructure adequately, assess capacity increases, and quantify the level of service and potential operating cost savings. It also enables sensitivity analysis while considering the impacts of real-world variables. Simulation may be seen as an invaluable tool to evaluate and understand performance capabilities, which can also accommodate real-world demand requirements (Garcia[8]).

We imitated the auto carrier operations using past data from a period equivalent to six months of operational time; the aggregated demand is shown in Table 2, while the distances to travel between two locations are shown in Table 3. The locations are labelled "CT", "DBN" etc., and the location "BFN" is an intermediate sink. The average daily demand between any two locations ranged from one car per day to 68 cars per day. In the model, auto carriers travel to destinations and experience offload and pick-up delays that are stochastic. Travel speeds were assumed to be an average of $64 \mathrm{~km} / \mathrm{h}$, while vehicles to be transported originated over time at various branches in the network, based on the historical data. The various scenarios were implemented in Arena, a simulation package of Rockwell Software (Rockwell Software[21]).

\begin{tabular}{c|rcccrr}
\hline \multicolumn{7}{c}{ To } \\
\hline From & \multicolumn{1}{c}{$C T$} & $D B N$ & \multicolumn{1}{c}{$E L$} & \multicolumn{1}{c}{$G P$} & \multicolumn{1}{c}{$P E$} & \multicolumn{1}{c}{$B F N$} \\
\hline$C T$ & - & 983 & 186 & 2329 & 345 & 115 \\
DBN & 10701 & - & 2009 & 12118 & 16310 & 2152 \\
$E L$ & 1173 & 3694 & - & 2511 & 402 & 7 \\
$G P$ & 7552 & 7183 & 1524 & - & 1644 & 1510 \\
$P E$ & 139 & 12618 & 2501 & 574 & - & 34 \\
\hline
\end{tabular}

Table 2: Total number of cars transported per route

\begin{tabular}{l|rrrrr}
\hline \multicolumn{7}{c}{ To } \\
\hline From & \multicolumn{1}{|c}{ DBN } & \multicolumn{1}{c}{ EL } & \multicolumn{1}{c}{ GP } & \multicolumn{1}{c}{ PE } & \multicolumn{1}{c}{ BFN } \\
\hline CT & 1660 & 1042 & 1405 & 756 & 998 \\
DBN & - & 667 & 598 & 927 & 628 \\
EL & - & - & 992 & 300 & 546 \\
GP & - & - & - & 1062 & 396 \\
PE & - & - & - & - & 676 \\
\hline
\end{tabular}

Table 3: Distance matrix of main routes $(\mathrm{km})$ 


\subsection{Simulation model verification and validation}

Model verification and validation were based on the work of Banks[3] and Law and Kelton[14]. In order to have confidence in the simulation models, approaches that were followed include the investigation of extreme cases, the incorporation of outside doubters such as an AC company subject matter expert (SME), executing the model with certain parameters set to certain values, and animation. The AC company verified the processed input data, and the data (orders released in the system) generated by the model were compared to the historical data by means of face validation, which can identify problems in terms of model logic and functioning, as well as correctness by means of inspection and experimentation (Banks[3]). The model behaviour and output were examined for a realistic portrayal of changes made to the model and model input according to factors such as continuity, consistency, degeneracy, and absurd conditions (Law and Kelton[14]).

\subsection{Evaluation parameters}

The quality of each of the scenarios had to be determined, and one or more performance measures were thus required. Some parameters of significance in the auto carrier context are mentioned by Tadei et al.[24]. They include the number of vehicles loaded (which contributes to the revenue), the number of unloading stops, and total vehicle tardiness (a lateness measure that incurs a cost).

The performance measures deemed most relevant to this study are shown and described in Table 4, some of which are conflicting in nature.

\begin{tabular}{|l|l|l|}
\hline $\begin{array}{l}\text { Performance } \\
\text { measure }\end{array}$ & Explanation & $\begin{array}{l}\text { Unit of } \\
\text { measurement }\end{array}$ \\
\hline $\begin{array}{l}\text { Average } \\
\text { queue length }\end{array}$ & $\begin{array}{l}\text { The time-weighted average of the queue of cars waiting } \\
\text { to be transported at each branch. It was aggregated for } \\
\text { all branches to determine a single figure that reflects a } \\
\text { country-wide situation. }\end{array}$ & \# vehicles \\
\hline Empty km & $\begin{array}{l}\text { The accumulated value of empty slots on each auto } \\
\text { carrier times the distance the auto carrier travelled } \\
\text { with each of the unfilled spaces. }\end{array}$ & Kilometres \\
\hline Useful km & $\begin{array}{l}\text { The accumulated value of loaded vehicles on an auto } \\
\text { carrier times the distance travelled by that auto carrier. }\end{array}$ & Kilometres \\
\hline Average time & $\begin{array}{l}\text { The average time an order spent in the system: the time } \\
\text { that an ordered vehicle waits, from arriving in the } \\
\text { system until delivered. }\end{array}$ & Hours \\
\hline
\end{tabular}

Table 4: Description of the performance measures

Maximising cost effectiveness (fewer empty kilometres relative to more useful kilometres) may imply that vehicles have to wait longer before being delivered. The kilometre measures are summed over the duration of the simulation run, and each slot on the auto carrier (empty or filled) appropriately contributes to these measures. These factors may perhaps not be useful in absolute terms (see the objection raised by Song and Savelsbergh[22]), but are considered adequate for the purposes of relative performance comparison.

In order to select from alternatives with multiple attributes, we used a multi-attribute decision-making (MADM) method to determine the best of the scenarios, while taking into consideration the four performance measures that are conflicting in nature and measured in different units. Generally, one selects from a discrete set $S$ of $m$ alternatives, having a set $P$ of $n$ additively independent attributes, $P=\left\{P_{1}, P_{2}, \ldots, P_{n}\right\}$. Weights may be associated with each attribute, and a weight vector is defined as $w=\left\{w_{1}, w_{2}, \ldots, w_{n}\right\}$, with $\sum_{j=1}^{n} w_{j}=1, \quad w_{j} \geq 0$. 
Many multi-attribute decision-making methods are available, e.g. the Simple Additive Weighting method (SAW) (Ma et al.[15]), and Total Order Preference by Similarity to the Ideal Solution method (TOPSIS), developed by Hwang and Yoon and described in Jahanshahloo et al.[10], which uses normalized attribute values that are aggregated into single numbers used for the ranking of alternatives. We selected the TOPSIS method because it allows for the assignment of weights to the attributes according to the various relevancies, and compares scenarios to relative ideal scenarios. To rank the scenarios according to TOPSIS, a decision matrix $A=\left[a_{i j}\right]_{\mathrm{m} \times n}$ is formed, where $a_{i j}$ is the numerical value for alternative $i$, associated with attribute $j, i=1, \ldots, m$ and $j=1, \ldots, n$. A normalised decision matrix is now formed as follows:

$r_{i j}=\frac{a_{i j}}{\sqrt{\sum_{i=1}^{m} a_{i j}^{2}}}, \quad i=1, \ldots, m, \quad j=1, \ldots, n$

The elements $v_{i j}$ of the weighted matrix $V$ are given by $v_{i j}=w_{j} r_{i j}, \quad i=1, \ldots, m, j=1, \ldots, n$. The positive (desirable) and negative (undesirable) similarities are given by

$$
\begin{aligned}
& V^{+}=\left\{v_{1}^{+}, \ldots, v_{n}^{+}\right\}=\left\{\left(\operatorname{Max}\left(v_{i j}\right), \mid j \in I\right),\left(\operatorname{Min}\left(v_{i j}\right), \mid j \in J\right)\right\} \\
& V^{-}=\left\{v_{1}^{-}, \ldots, v_{n}^{-}\right\}=\left\{\left(\operatorname{Min}\left(v_{i j}\right), \mid j \in I\right),\left(\operatorname{Max}\left(v_{i j}\right), \mid j \in J\right)\right\}
\end{aligned}
$$

where $I$ is associated with the positive attributes and $J$ is associated with the negative attributes. Now determine the positive and negative separation measures using the $n$ dimensional Euclidean distance:

$$
\begin{aligned}
& D_{i}^{+}=\sqrt{\sum_{j=1}^{n}\left(v_{i j}-v_{j}^{+}\right)^{2}}, \quad i=1, \ldots, m \\
& D_{i}^{-}=\sqrt{\sum_{j=1}^{n}\left(v_{i j}-v_{j}^{-}\right)^{2}}, \quad i=1, \ldots, m
\end{aligned}
$$

Finally, calculate the relative closeness of each alternative to the ideal alternative, and rank each according to the outcome of this calculation, in descending order:

$$
\bar{D}_{i}=\frac{D_{i}^{-}}{D_{i}^{+}+D_{i}^{-}}, \quad i=1, \ldots, m
$$

\section{RESULTS AND ANALYSIS}

The expected values of each performance measure for each of the 45 scenarios were estimated using 10 independent simulation runs, which were found to provide sufficient $95 \%$ confidence intervals per performance measure. The results obtained from the simulation runs for each scenario are shown in Table 5, where 'Label' is a unique identifier for each scenario, 'Policy class' refers to the roaming order-picking rule in combination with the waiting rule, '\%R' shows the percentage of the fleet that was chosen to roam, and '\% $\mathrm{F}$ ' is the fixed fleet percentage. The output columns agree with the performance measures in Table 4. 


\begin{tabular}{|c|c|c|c|c|c|c|c|}
\hline \multicolumn{4}{|c|}{ Scenario description } & \multicolumn{4}{|c|}{ Scenario output (estimated means) } \\
\hline Label & $\begin{array}{l}\text { Policy } \\
\text { Class } 1\end{array}$ & $\begin{array}{l}\text { Policy } \\
\text { Class } 2\end{array}$ & \%R/\%F & Avg QL & $\begin{array}{l}\text { Useful km } \\
(/ 1000)\end{array}$ & $\begin{array}{l}\text { Empty km } \\
(/ 1000)\end{array}$ & $\begin{array}{l}\text { Avg t } \\
\text { (h) }\end{array}$ \\
\hline $\mathrm{A} 1$ & $\mathrm{a}$ & $a$ & $0 / 100$ & 1234 & 64602 & 49993 & 284 \\
\hline A2 & $\mathrm{a}$ & $\mathrm{a}$ & $25 / 75$ & 1786 & 57937 & 27797 & 548 \\
\hline A3 & $\mathrm{a}$ & $\mathrm{a}$ & $50 / 50$ & 2577 & 50335 & 13843 & 874 \\
\hline A4 & $a$ & $\mathrm{a}$ & $75 / 25$ & 3450 & 42487 & 10027 & 1168 \\
\hline A5 & $a$ & $\mathrm{a}$ & $100 / 0$ & 3866 & 39480 & 7807 & 1233 \\
\hline A6 & $a$ & $\mathrm{~b}$ & $0 / 100$ & 1267 & 64007 & 50140 & 272 \\
\hline A7 & $\mathrm{a}$ & $\mathrm{b}$ & $25 / 75$ & 859 & 76163 & 48292 & 294 \\
\hline A8 & $\mathrm{a}$ & $\mathrm{b}$ & $50 / 50$ & 447 & 85063 & 47462 & 178 \\
\hline A9 & $\mathrm{a}$ & $\mathrm{b}$ & $75 / 25$ & 233 & 87753 & 52087 & 99 \\
\hline A10 & $a$ & $b$ & $100 / 0$ & 210 & 88316 & 55561 & 88 \\
\hline A11 & $a$ & C & $0 / 100$ & 1196 & 64322 & 49105 & 266 \\
\hline A12 & $a$ & C & $25 / 75$ & 776 & 76704 & 47617 & 286 \\
\hline A13 & $a$ & C & $50 / 50$ & 403 & 83400 & 43280 & 167 \\
\hline A14 & $a$ & C & $75 / 25$ & 253 & 85696 & 40490 & 116 \\
\hline A15 & $a$ & C & $100 / 0$ & 240 & 86619 & 39401 & 105 \\
\hline B1 & $b$ & $a$ & $0 / 100$ & 1105 & 65343 & 49465 & 243 \\
\hline B2 & $b$ & $a$ & $25 / 75$ & 1588 & 58122 & 26613 & 506 \\
\hline B3 & $b$ & $a$ & $50 / 50$ & 2241 & 53266 & 15883 & 776 \\
\hline B4 & $b$ & $a$ & $75 / 25$ & 2980 & 46171 & 12771 & 1057 \\
\hline B5 & $b$ & $a$ & $100 / 0$ & 3352 & 44071 & 10832 & 1061 \\
\hline B6 & $b$ & $b$ & $0 / 100$ & 1267 & 64007 & 50140 & 287 \\
\hline B7 & $b$ & $b$ & $25 / 75$ & 904 & 76156 & 47776 & 323 \\
\hline B8 & $b$ & $b$ & $50 / 50$ & 424 & 85651 & 47473 & 180 \\
\hline B9 & $b$ & $\mathrm{~b}$ & $75 / 25$ & 237 & 88155 & 52633 & 106 \\
\hline B10 & $b$ & $b$ & $100 / 0$ & 198 & 88222 & 56421 & 86 \\
\hline B11 & $b$ & C & $0 / 100$ & 1253 & 64100 & 50265 & 285 \\
\hline B12 & $b$ & C & $25 / 75$ & 780 & 76443 & 47474 & 293 \\
\hline B13 & $b$ & C & $50 / 50$ & 382 & 83124 & 42795 & 162 \\
\hline B14 & $b$ & C & $75 / 25$ & 263 & 85224 & 39706 & 122 \\
\hline B15 & $b$ & C & $100 / 0$ & 241 & 86368 & 38788 & 106 \\
\hline C1 & C & $a$ & $0 / 100$ & 1105 & 65286 & 49527 & 242 \\
\hline C2 & C & $a$ & $25 / 75$ & 1315 & 64030 & 30331 & 424 \\
\hline C3 & C & $a$ & $50 / 50$ & 1867 & 58271 & 16021 & 611 \\
\hline C4 & C & $a$ & $75 / 25$ & 2235 & 52562 & 11974 & 734 \\
\hline C5 & C & $a$ & $100 / 0$ & 2714 & 49450 & 9633 & 804 \\
\hline C6 & C & $\mathrm{b}$ & $0 / 100$ & 1179 & 64635 & 49467 & 260 \\
\hline C7 & C & $b$ & $25 / 75$ & 758 & 76804 & 46704 & 282 \\
\hline C8 & C & $\mathrm{b}$ & $50 / 50$ & 336 & 85358 & 47566 & 154 \\
\hline C9 & C & $b$ & $75 / 25$ & 177 & 88391 & 50891 & 87 \\
\hline C10 & C & $b$ & $100 / 0$ & 147 & 88650 & 55984 & 71 \\
\hline C11 & C & C & $0 / 100$ & 1179 & 64635 & 49467 & 260 \\
\hline C12 & C & C & $25 / 75$ & 822 & 75882 & 46923 & 296 \\
\hline C13 & C & C & $50 / 50$ & 520 & 80580 & 40625 & 199 \\
\hline C14 & C & C & $75 / 25$ & 553 & 81491 & 35512 & 215 \\
\hline C15 & C & C & $100 / 0$ & 616 & 81692 & 33912 & 227 \\
\hline
\end{tabular}

Table 5: Summary of simulated scenario results

We assumed that in each scenario the confidence intervals cover the true means, although the Bonferroni inequality states that for $k$ performance measures and $1-\alpha_{i}$ confidence levels, the probability that all the confidence intervals cover the respective true means simultaneously is given by (Law and Kelton[14]): 


$$
P\left(\mu_{k} \in I_{k}, k=1, \ldots, n\right) \geq 1-\sum_{k=1}^{n} \alpha_{i}
$$

The alternative with the highest value for $\bar{D}_{i}$ is the best. The scenario ranking for this study according to the TOPSIS analysis is given in Table 6.

\begin{tabular}{|c|c|c|c|c|c|c|c|c|}
\hline \multicolumn{9}{|c|}{ TOPSIS Analysis } \\
\hline Rank & Scenario & $\bar{D}_{i}$ & Rank & Scenario & $\bar{D}_{i}$ & Rank & Scenario & $\bar{D}_{i}$ \\
\hline 1 & A15 & 0.8174 & 16 & C10 & 0.7531 & 31 & A1 & 0.6620 \\
\hline 2 & A14 & 0.8105 & 17 & A10 & 0.7516 & 32 & A6 & 0.6610 \\
\hline 3 & B14 & 0.7997 & 18 & B10 & 0.7488 & 33 & B11 & 0.6588 \\
\hline 4 & C14 & 0.7997 & 19 & C7 & 0.7226 & 34 & B6 & 0.6573 \\
\hline 5 & B15 & 0.7992 & 20 & A12 & 0.7169 & 35 & B2 & 0.6096 \\
\hline 6 & C15 & 0.7992 & 21 & B12 & 0.7152 & 36 & $\mathrm{~A} 2$ & 0.5685 \\
\hline 7 & A13 & 0.7839 & 22 & C12 & 0.7129 & 37 & C3 & 0.5582 \\
\hline 8 & B13 & 0.7824 & 23 & A7 & 0.7057 & 38 & C4 & 0.4778 \\
\hline 9 & C13 & 0.7824 & 24 & B7 & 0.6964 & 39 & B3 & 0.4557 \\
\hline 10 & C8 & 0.7707 & 25 & B1 & 0.6854 & 40 & C5 & 0.4096 \\
\hline 11 & C9 & 0.7697 & 26 & C1 & 0.6854 & 41 & $\mathrm{~A} 3$ & 0.3915 \\
\hline 12 & B8 & 0.7632 & 27 & C11 & 0.6746 & 42 & B4 & 0.3066 \\
\hline 13 & A8 & 0.7639 & 28 & C6 & 0.6746 & 43 & B5 & 0.2841 \\
\hline 14 & A9 & 0.7638 & 29 & A11 & 0.6725 & 44 & A4 & 0.2634 \\
\hline 15 & B9 & 0.7608 & 30 & C2 & 0.6672 & 45 & A5 & 0.2486 \\
\hline
\end{tabular}

Table 6: TOPSIS results

When examining the results, it seems that a 50 to $100 \%$ Roaming fleet is more favourable, and the policy that specifies that auto carriers do not wait for work at the smaller branches appears in general to be beneficial. Although more attractive fleet composition alternatives may be identified, it is nevertheless evident from the results that the outcome for each scenario depends not on just one policy or on the fleet composition alone, but also on the particular combination of policies and the specific fleet composition.

\section{REFINING THE RESULTS FOR TACTICAL DECISION SUPPORT}

The results were analysed further to obtain different views for tactical decision support. The decision-maker may use the ranked scenarios to select a preferred fleet composition and operational planning policy, or identify more desirable and less desirable tendencies. Additionally, different weights may be used to differentiate between the importance of the performance measures.

Visual aids may also be consulted to gain more insight regarding the fleet management of long-distance auto carriers. We propose a fleet portfolio efficient frontier, an analogy to the efficient frontier from investment theory (Markowitz[16]), that can assist the decisionmaker to determine a good fleet composition. When considering the most suitable or preferable fleet composition, a 'fleet portfolio' may be selected by introducing an analogy to the efficient frontier. In this context, 'Fixed' and 'Roaming' auto carriers are two securities, while there are only a limited number of auto carriers to 'invest' in either a Fixed or a Roaming fleet. The number of auto carriers would therefore be the 'capital' invested.

The risk associated with the return of a particular 'investment' was also investigated in the case of the AC problem. In this context the composition of an investment (the specific \% and \% $\mathrm{F}$ carrier fleet) may be viewed as the 'risk' associated with attaining an expected outcome for that investment. An efficient frontier analogue may then be constructed to 
facilitate fleet portfolio selection, portraying the deviation or spread in expected outcome for a particular Roaming/Fixed investment. This concept is explained in Figure 2.

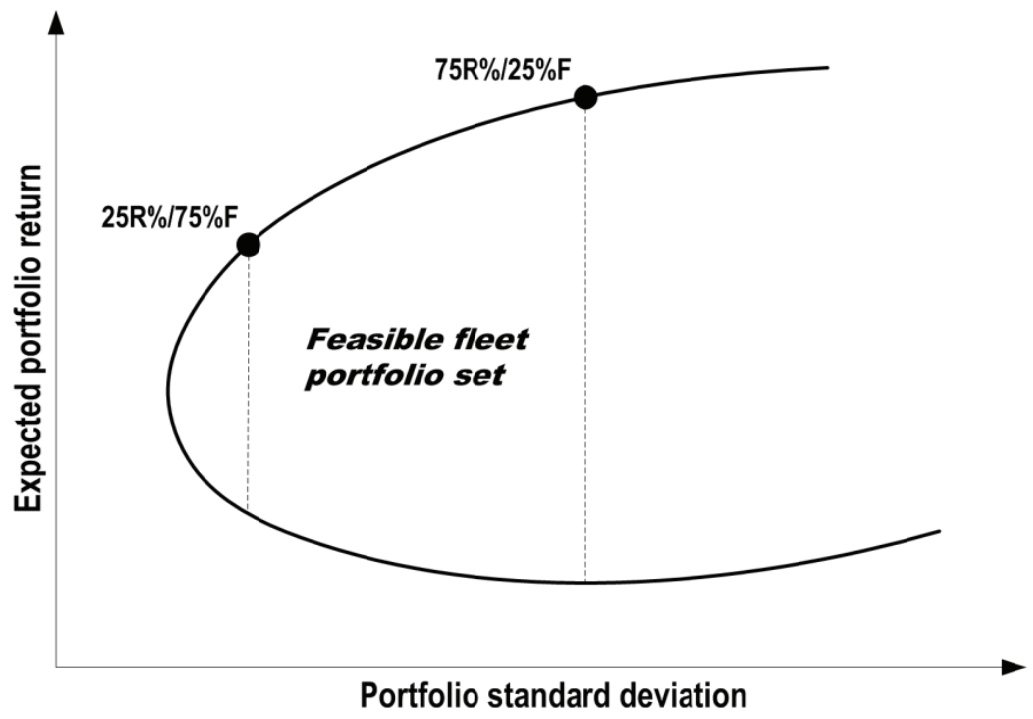

Figure 2: AC efficient frontier analogue

The expected outcome for each scenario in this study was obtained by applying the TOPSIS method to determine a non-financial 'expected return' value. The graph in Figure 3 is similar to the efficient frontier in Figure 2.

In Figure 3 the data points show the TOPSIS results of the 45 scenarios. It may be noticed that with an increase in roaming auto carriers, a greater overall return may be expected, although the variation in the outcome is also greater. Therefore, the risk of not getting the expected return is higher when greater return may be expected. The possible return is evidently much more policy-dependent for a greater Roaming fleet than for Fixed auto carriers.

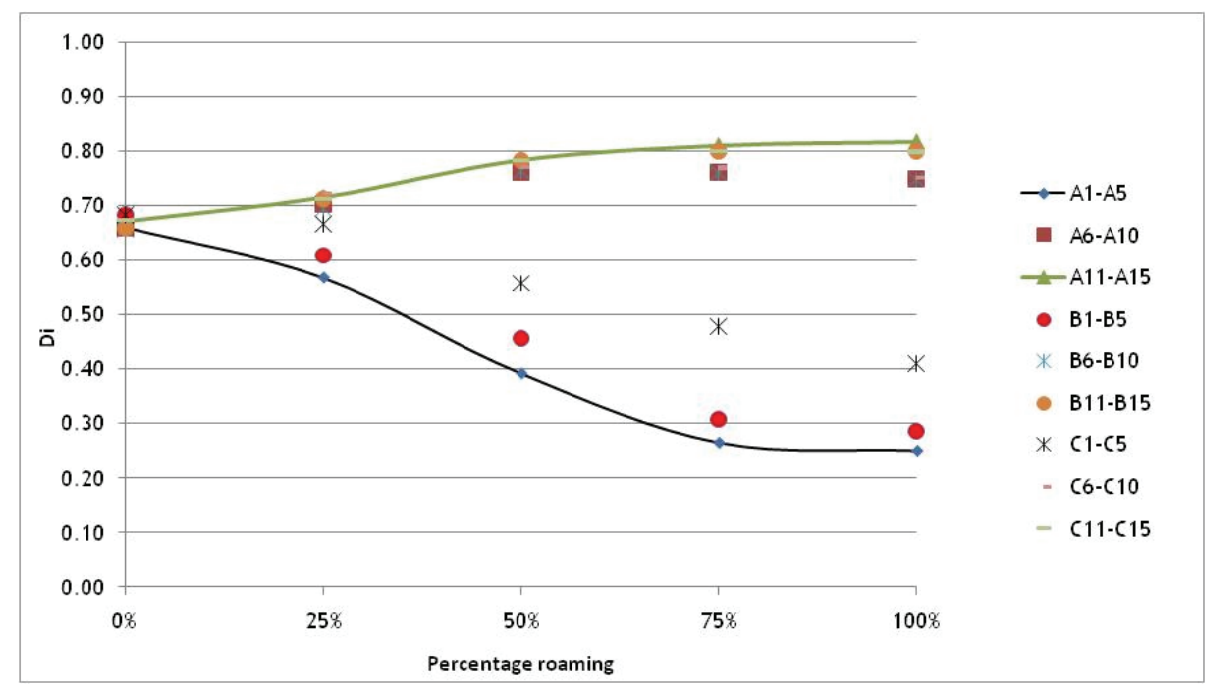

Figure 3: Fleet portfolio efficient frontier 
Fewer roaming auto carriers may bring a more certain return for any operations policy, although not as high a return as a bigger roaming fleet should achieve. A risk-averse decision-maker might favour fixed auto carriers or a $25 \%$ roaming fleet, whereas a risk seeker could be interested in a $75 \%$ to $100 \%$ roaming investment.

The fleet portfolio efficient frontier also indicates which policy combinations are most suitable for each fleet composition. These are shown in Table 7.

\begin{tabular}{|c|r|c|}
\hline Scenario & \% Roaming & $\bar{D}_{i}$ \\
\hline $\mathrm{A} 15$ & 100 & 0.8174 \\
\hline $\mathrm{A} 14$ & 75 & 0.8105 \\
\hline $\mathrm{A} 13$ & 50 & 0.7839 \\
\hline $\mathrm{C} 7$ & 25 & 0.7226 \\
\hline $\mathrm{B} 1$ & 0 & 0.6854 \\
\hline
\end{tabular}

Table 7: Best fleet portfolios

The roaming order-picking policy 1.b, which considers the order priority in the queue when deciding on a next best destination, in combination with no waiting for work at the smaller branches, outperforms the other scenarios for a fleet composition of 50 to $100 \%$ Roaming. When there are no roaming auto carriers, the roaming order-picking policies do not play a role, and although B1 appears to be most favourable (included in Table 7), the results of scenarios B1, A1, and C1 are very close to each other (refer to Table 6), where C1 has exactly the same value as B1.

The only performance measure available from the AC company is the average delivery time per vehicle, which is 110 hours. The quality of the scenarios can be compared against this value: suppose a weight of 0.5 is associated with the delivery time, and the other three weights are equally distributed for the other three performance measures (i.e. 0.167 each), then the ranking for the top 10 scenarios changes compared with Table 6; see Table 8 . Seven scenarios predict an improved delivery time, while three are worse, and the decision-maker can now decide which of the best seven to use.

\begin{tabular}{ccr}
\hline Scenario & $\bar{D}_{i}$ & Avg t $(\mathrm{h})$ \\
\hline $\mathrm{A} 15$ & 0.9039 & 105 \\
\hline $\mathrm{A} 14$ & 0.8978 & 116 \\
\hline $\mathrm{C} 9$ & 0.8787 & 87 \\
\hline $\mathrm{A} 9$ & 0.8735 & 99 \\
\hline $\mathrm{B} 9$ & 0.8708 & 106 \\
\hline $\mathrm{A} 13$ & 0.8692 & 167 \\
\hline $\mathrm{C} 10$ & 0.8683 & 71 \\
\hline $\mathrm{A} 10$ & 0.8670 & 88 \\
\hline $\mathrm{C} 8$ & 0.8669 & 154 \\
\hline $\mathrm{B} 10$ & 0.8653 & 86
\end{tabular}

Table 8: Scenario rankings with larger weight on delivery time

\section{SUMMARY AND CONCLUSIONS}

Distributing vehicles from ports of import and manufacturers is a freight transportation operation. We presented a specific case in a developing country and investigated the feasibility of allowing part of the auto carrier fleet to roam the closed spatial network, as opposed to assigning them to fixed routes. The roaming auto carriers must follow decisionmaking guidelines on the operational level, because they move from node to node in the network, and each node presents a unique situation at each decision epoch. 
We developed rules for decision-making by roaming auto carriers, and also added new waiting-at-branch policy rules for both fixed and roaming auto carriers. The quality of these proposed rules, in combination with different fleet compositions, was evaluated using discrete event simulation. We used real (historic) data of vehicle orders to drive the model, and identified four performance measures. These were combined into a single dimensionless measure using the TOPSIS method, allowing for the relative ranking of the 45 simulation scenarios.

Studies of this type of problem are available in the literature, and researchers often include or exclude aspects of the problem - e.g., whether the trucks are homogenous or not. In this study, we worked with a finite fleet operating in a closed spatial network of routes connecting branches (nodes), while orders for transport emerged over time. An auto carrier can serve more than one order at a time and, due to the nature of the freight (vehicles), the auto carriers (trucks) are non-homogenous. We allowed for less-than-truckload movements, and infinite but penalised backlogging, while strictly adhering to driver labour requirements and truck service schedules.

We recommend that the $\mathrm{AC}$ company adopt a tactical operations policy where at least $50 \%$ of the auto carriers are allowed to roam, while roaming auto carriers pick vehicles according to priority in the vehicle queue or most work in the queue at a node, and fixed and roaming auto carriers do not wait for work at the smaller branches.

It will of course be necessary to train employees to understand and accept these policies, and then implement and execute them. As the market demand grows, the AC company should repeat the analysis and adapt the appropriate operational policies accordingly. This ability to adjust is a valuable result of this case study.

\section{REFERENCES}

[1] Agbegha, G.Y., Ballou, R.H. \& Mathur, K. 1998. Optimizing auto-carrier loading, Transportation Science 32, pp. 174-188.

[2] Andersen, J., Crainic, T.G. \& Christiansen, M. 2009. Service network design with management and coordination of multiple fleets, European Journal of Operational Research 193, pp. 377-389.

[3] Banks, J. 1998. Handbook of simulation: Principles, methodology, advances, applications, and practice, John Wiley and Sons Inc.

[4] Branke, J., Middendorf, M., Noeth, G. \& Dessouky, M. 2005. Waiting strategies for dynamic vehicle routing, Transportation Science 39, pp. 298-312.

[5] Carvalho, T.A. \& Powell, W.B. 2000. Multiplier adjustment method for dynamic resource allocation problems, Transportation Science 34, pp. 150-164.

[6] Crainic, T.G. \& Laporte, G. 1996. Planning models for freight transportation, European Journal of Operational Research 97, pp. 409-438.

[7] Doerner, K.F., Fuellerer, G., Hartl, R.F., Gronalt, M. \& lori, M. (2007). Metaheuristics for the vehicle routing problem with loading constraints, Networks 49(4), pp. 294 - 307.

[8] Garcia, B.R. 2005. Keeping up with cargo: Simulation provides alternative ports of call, Industrial Engineer 41, pp. 669-693.

[9] Hickman, M.D. 2001. An analytic stochastic model for the transit vehicle holding problem, Transportation Science 35, pp. 215-237.

[10] Jahanshahloo, G.R., Lotfi, F.H. \& Izadikhah, M. 2006. An algorithmic method to extend TOPSIS for decision-making problems with interval data, Applied Mathematics and Computation 175, pp. 1375-1384.

[11] Krajewska, M.A. \& Kopfer H. In press. Transportation planning in freight forwarding companies: Tabu search algorithm for the integrated operational transportation planning problem, European Journal of Operational Research, doi:10.1016/ j.ejor.2008.06.042.

[12] Laporte, G. 2007. What you should know about the vehicle routing problem, Naval Research Logistics 54, pp. 811-819. 
[13] Laporte, G., Gendreau, M., Potvin, J. \& Semet, F. 2000. Classical and modern heuristics for the vehicle routing problem, International Transactions in Operations Research 7, pp. 285-300.

[14] Law, A.M. \& Kelton, W.D. 2000. Simulation modeling and analysis, $3^{\text {rd }}$ edition, McGraw-Hill.

[15] Ma, J., Fan, Z. \& Huang, L. 1999. A subjective and objective integrated approach to determine attribute weights, European Journal of Operational Research 112, pp. 397-404.

[16] Markowitz, H. 1952. Portfolio theory, The Journal of Finance 7, pp. 77-91.

[17] Mes, M., van der Heijden, M. \& van Harten, A. 2007. Comparison of agent-based scheduling to look-ahead heuristics for real-time transportation problems, European Journal of Operational Research 181, pp. 59-75.

[18] Mitrović-Minić, S. \& Laporte, G. 2004. Waiting strategies for the dynamic pickup and delivery problem with time windows. Transportation Research Part B 38, p.635655.

[19] Moreno-Quintero, E. 2006. Optimal control of road freight flows by route choice inducement: A case from Mexico, European Journal of Operational Research 175, pp. 1588-1604.

[20] Powell, W.B., Snow, W. \& Cheung, R.K. 2000. Adaptive labeling algorithms for the dynamic assignment problem, Transportation Science 34, pp. 50-66.

[21] Rockwell Software. 2009. http://www.arenasimulation.com. Accessed 10 April 2010.

[22] Song, J. \& Savelsbergh, M. 2002. Performance measurement for inventory routing, Transportation Science 41, pp. 44-54.

[23] Sorensen, K. 2006. Route stability in vehicle routing decisions: A bi-objective approach using metaheuristics, Central European Journal of Operations Research 14, pp. 193-207.

[24] Tadei, R., Perboli, G. \& Della Croce, F. 2002. A heuristic algorithm for the autocarrier transportation problem, Transportation Science 36, pp. 55-62.

[25] Thomas, B. 2007. Waiting strategies for anticipating service requests from known customer locations. Transportation Science 41, pp.319-331.

[26] Toth, P. \& Vigo, D. 2000. The vehicle routing problem, Society for Industrial and Applied Mathematics (SIAM).

[27] Wu, P., Hartman, J.C. \& Wilson, G.R. 2005. An integrated model and solution approach for fleet sizing with heterogenous assets, Transportation Science, 39, pp. 87-103.

[28] Yang, J., Jaillet, P. \& Mahmassani, H. 2004. Real-time multivehicle truckload pickup and delivery problems, Transportation Science 38, pp. 135-148. 
http://sajie.journals.ac.za 